\title{
YOUNG SÁMI MEN ON THE MOVE: ACTORS, ACTIVITIES, AND
}

\section{AIMS FOR THE FUTURE}

\begin{abstract}
In this study, we have been interviewing eight young Sámi men about experience with ruralurban and majority-minority transition. The analyses revealed that the transition affected three dimensions in their life; actors, activities, and aims for the futures. The important actors transformed from relatives to friends. Desirable duties transformed to leisure and sports activities. The transformation of aims for the future was guided by birget (to manage or to handle); a Sámi concept meaning to cope in your life, both independently and together with others. We suggest that social workers can use the three A's (actors, activities, and aims for the future) in an intervention to enhance the well-being for indigenous young men on the move.
\end{abstract}

\section{Keyword:}

Sámi men, indigenous men, masculinity, moving, rural Indigenous village

\section{Introduction}

In this study, the aim is to investigate how young North Sámi men manage and handle a transformation from adolescents to adult life and from a familiar Sámi rural village to an urban city. We have been asking how they were coping during the moving processes and their reflection concerning enhancement and challenges in these processes. In order to discuss these issues, we have been interviewing eight young North Sámi men from a small Sámi village where the majority of the population are Sámi. These men had to move from the Sámi village 
to a city, where they are a minority, due to education or job. We chose this sample because it represents young Sámi men that managed the transition.

The participators are Sámi men, and all have strong affiliation to the Sámi lifestyle, Sámi language, and Sámi way of living. Even though the number of participants in this study are small, and they are all from one indigenous group, we will argue that the results are applicable for indigenous men around the world. They are facing similar challenges and the participants are tuning in on the themes in their reflection that are likely to concerns indigenous young men around the world.

The Sámi are indigenous people living in multi-ethnical regions of Norway, Sweden, Finland, and Russia. In Norway, the Sámi society is divided in three different Sámi language; the northern Sámi; Lule Sámi; and Southern Sámi. Traditionally, the Sámi were reindeer herders, or lived of fishing, farming or a combination of fishing and farming. The modernization of traditional life forms and the harsh assimilation politics has changed the Sámi life form (Eidheim, 1987; Minde, 2016). Many young Sámi men have been alienated to Sámi lifeform due to these processes in recent year, as the modern life form in the traditional trade has room for fewer participants. Hence, less young Sámi men can expect life-prospects within the traditional life form. The sedentarization among Sámi men in Sámi villages in the North Sámi region is still high (Nystad, 2003; Sørlie \& Broderstad, 2011). This is one the reasons why less Sámi men take higher education, compared to Sámi females (Johansen, Kvernmo, Spein, \& Silviken, 2003). 


\section{Theoretical frame: Young Sámi men on the move}

Indigenous people across the world have suffered harsh colonization and assimilation with considerable negative consequences (I. Anderson et al., 2006; Armenta, Whitbeck, Habecker, \& Lee, 2016; King, Smith, \& Gracey, 2009). Colonization is a concept covering a complexity as it includes social-historical processes and are the subject of multiple discourses and it can be understood in multiple ways. The most common is to understand it in line with settlements; the origin people have their land taken over by newcomers, se for example Wolfes discussion of the complexity settler colonialism (2013). Another form is "colonization of mind" describing how native knowledge is ignored, suppressed, and socialized into the dominant society, as Keskitalo, Määatä, and Uusiautti (2011) describe concerning Sámi education. Yet another form is "welfare colonization" (Paine 1977, Olsson and Lewis 2002). In the Nordic states, the criticism is that welfare state actually is a form for colonization because the only way to get access to the welfare is by using the dominate states system. Despite providing recourses and access to political influence that indigenous people elsewhere "only can envy" (Kuokkanen, 2009) the welfare state gives no room for taking traditional system in the indigenous society and collective as a starting point. At the contrary, engaging in the indigenous way of living becomes a disadvantage for taking part of the benefits provided by the welfare state (Payne 1977, Olsson and Lewis, 2002, Kuokkanen 2009). The young Sámi men we have been taking to in this study tells stories fitting into the welfare colonialism concept. They have been structural forced to move from their home town to the city in order to get education, which is considered a right and a possibility for all youth in Norway; in order to get a job, in a land with very low unemployment; in order to have a future prospect, in a land where the common future optimism is very high. The diaspore situation they describe; forceful on the move, they find themselves in, are a situation they do not share with most young men in Norway. Hence, long-term effect of welfare colonialism is a theoretical 
frame to both to analyze the young Sámi men's stories, but also to see the link between the historical political assimilation towards the Sámi people and their individual life stories today.

Health problems, poverty, drug related problems, and suicidality are among the negative consequences of colonization and assimilation (Griffiths, Coleman, Lee, \& Madden, 2016; Zhao, You, Guthridge, \& Lee, 2011). It also caused chances in indigenous societies, changes in gender role pattern, and led to low self-esteem for many indigenous people (Kirmayer, Brass, \& Tait, 2000; Silviken, 2009). One of the many long-term effect of colonialization and suppression of indigenous people is that young indigenous men have poorer psychological health compared to other men. In Norway, the harsh political strategy called norwegization politic aiming to assimilate the Sámi people until the mid-sixties with severe long-term effects (Minde, 2016). In the same way as Indigenous men around the world, the young North Sámi men have a higher risk to develop health problems, suicide, drop-out from education and unemployment compared to other groups (I. Anderson et al., 2006; Atkinson, 2002; Bania, 2017; Broderstad, Brustad, Johansen, Severeide, \& Todal, 2015; Granseth, 2015; King et al., 2009).

The long-term effect of the welfare colonialism means that many indigenous young men have to move from their rural hometown to the urban cities. They move from a village where they are a majority to a city where they live as a minority. Due to the life-expectation of remain in the traditional life form and remain living in the village, more often than others, the young Sámi men have to reorganize their identities and life-prospects. This gives them a weaker base entering the adult life. Thus, to diminish the long-term effect of colonization and assimilation of indigenous people, enhancing young indigenous men on the move from adolescents to 
adulthood and from the acquaintance hometown to the alienated city, is a weighty effort. Interventions that aim to enhance a safe rural-urban and majority-minority migration for young indigenous men are significant to provide well-being for indigenous young men forced to move due to job or education.

The young Sámi men are moving in more than one respect, both in space, time, and from boys to men. In these processes, they experience that multiple identities are crossing and giving directions at the same time. The two Sámi concepts almmáivuohta (manliness or masculinity) and almmáiduvvat (to become a man) are relevant to understand the development of identity for young Sámi men. Almmáiduvvat is to achieve his power and mastering activities on his own (Nystad, 2003). These concepts shed light over the transition to become a man and the expected competence of young Sámi men. Masculinity are one way for young indigenous men to display their indigenous identity (K. Anderson \& Innes, 2015). The city provides places to perform indigenous manliness that both for new ways to create indigenous narratives, but also to maintain a connection to the social groups in the traditional hometown. How do they handle that the transition from boy to man is coincident with the transition from the familiar to the unfamiliar? Which room do they make for themselves as men, as indigenous person, as a young adult? These questions point towards a constructive perspective on masculinity; high lightening how the young Sámi men are doing masculinity and how do they construct themselves to be men.

In resent year research about indigenous urbanity have reviled the complexity of indigenous identity and belonging. In different ways, and supported by different empirical data, they describe how the city both can be a hostile environment for Indigenous population and create 
room for belonging gives multiple - and new - narratives for indigenous identities (Dankertsen, 2014; Gjerpe, 2013; Nyseth \& Pedersen, 2014; Peters \& Andersen, 2013). Hence, the role of the city is interesting in order to understand how young indigenous men on the move.

Despite the challenges for the young Sámi men on the move described in the introduction, other have described how the transfer may open intercultural room in the grey zone between the familiar and the unfamiliar (Dankertsen, 2014, p. 187). These are creative rooms where new identities raise. The young men, moving to the urban cities where they have to adapt in an environment where they are a minority, give the men a chance to reinvent their identity, and form it according to the available symbols, structures, and institutions. The young men find themselves in environment where their traditional and cultural heritage are less visible or not visible at all. It leaves them some choices; to adopt whatever symbols, structures, and institutions the majority holds valuable, dissociate themselves from the majorities' valuables, or reinvent themselves within these environments. Stuart Hall has described cultural identity as ongoing process. Cultural identity is something being continuous created. It is a process heading towards the future becoming, rather than todays` being. Cultural identity are identification and ongoing, and not something you are or something inherited (Hall, 1996).

The Sámi concept birget (managing or handling) is a concept that helps us direct our analyses toward the intimate relation between empowerment and social interaction. Birget means to manage or handle all life aspects together with others. It covers area like manage and handle the private economy, to manage and handle your household, and manage and handle difficulties, always emphasizing togetherness (Boine 2007). Sámi fathers have birget as the 
most important goal of the upbringing (Boine \& Saus 2012). It is not to be best or to succeed; it is not competitive, and it is not individualistic. While achieving good results and having a high degree of self-consciousness seems to be a goal of western child upbringing, the Sámi fathers aim for independence and a relational competence. They teach the young men that birget is a desirable competence.

\section{Method}

We chose to use a qualitative design because it is suitable to investigate problems concerning experiences (Thagaard, 2009). It is also useful when investigating aspects concerning multicultures and genders (Denzin \& Lincoln, 2006). We used the snowball method to recruit the participants. We contacted a few, and let the word spread throughout the Sámi network in the city. Additionally, we gave strategic information about the study to Sámi adolescents and young adults, Sámi networks and formal and informal Sámi organizations, and we took direct contact with some potential participators. The targeted participants were young Sámi men that have moved from a village where the Sámi are a majority to a city where they are a minority. We did not prerequisite that they had especially challenges, rather we aimed for regular young Sámi men and their stories about how they handled and experienced to move and their reflections concerning this process.

The data for this study is individual, retrospective interviews. The interviewer used an interview guide but followed other topics if the participators brought up themes not in the guide. We asked them about their upbringing, how they handled the moving process, and their reflection about identity. The interview was either in Norwegian or Sámi language; depending on the participants own wishes. Efforts were done to make the interview situations to 
knowledge sharing situations, to make the interviews as comfortable as possible, and to meet the participants with respect and reciprocity, in line with the recommendation outlined by indigenous researcher as Kuokkanen (2000) Porsanger (2004) and Smith (1999).

We got the interviews transcribed, translated and analyzed in both Norwegian and Sámi language. This had two reasons. First, the double analyses represented a quality assurance of the interpretation. Second, the participators in the study have lived a life as bilingual language users, and we would expect them to mix expressions patters from the two cultures. The patterns we are outlining in the results and that carries the discussions, are appearing from the participants' stories. Using both languages in the methodical strategies, those stories can be discussed in accordance with the contextual frames where they make sense (Braun \& Clarke, 2006).

We used the snowball method to recruit the participants. We also informed Sámi associations in two cities about the study. The analytical strategy was to interpret the participant's stories in order to understand the transition from village to city. To find patterns in the data we coded their stories according to contents, relationships, time line and emotional expressions. The contents codes were experiences from schools at any level; leisure time; activities they liked and disliked; and other experiences. The relationships code hold stories about families; kin; friends; important persons; and other persons appearing in any of the interviews. The time line was an important part of the analyses because we could read the transformation in the historical dimension of their stories. We also draw a line from childhood to current time and placed. By doing this, we got a clear picture of the moving process, and it reviled how the participant handled the process before and after the actual relocation. The expression 
conducted samples of information about being sad, happy, enjoying themselves, anxious and so on. This expression codes added information in relation to activities, relationships and their aims and gave support to our interpretation of the participant's stories. In the analytical process, we saw the three codes; experiences, relationships, and time line in relation to background data as education, work, civil status, family background, and economical situation.

The strength in our methodical process was that an interviewer that speaks the north Saami language fluently did the interviews. The participants stressed this in the interviews and highlighted that they found it easier to be open and honest and sincere about how they felt about moving from their home village to the city. It might be a weakness that the interviewer was a female interviewing young men. However, the interviewer has a long career as a social worker before being a researcher and have a lot of experienced talking to young men and female about their situations. We believe that these skills help minimizing the potential weakness of the gender differences between the participants and the interviewer.

"Gender studies and indigenous studies share a tradition of reflexivity. As a scholar, you are expected to tell your audience of listeners or readers who you are and why you are doing the research you do".", as (Olsen, 2017, p. 521) formulated it in one of his indigenous studies. We are two women with different affiliations to the Sámi societies. One of the authors has Sámi heritage and has Sámi as her mother tongue, the other is married to a Sámi man. Both are mothers of young Sámi men. The Sámi speaking researcher conducted all the interviews in both Sámi and Norwegian languages and did the initial analyses and the analyses in the Sámi language. The other researcher conducted the second analyses in Norwegian. The 
writing process was mutual and characterized by back and forth. The process kept the closeness between the choice of word and the analytical interpretation of the meaning.

The study had all the ethical approvals that are required. To avoid strategies and procedures that appear not to be respectful or in other ways be inappropriate for young Sámi men, we discussed the procedures and the questions with young Sámi men in advance.

\section{Presentation of the participants}

They participators was young Sámi men from 21-25-years-old. We will not present them by depersonalized name and age. The Sámi community in Norway have a very low populated density. Hence, even pseudonym naming would jeopardize the promised anonymity.

The eight young Sámi participating had no overwhelming negative experience related to the moving process. The interviews were conducted in two cities in Northern-Norway depended on where the men currently lived. Some had lived in the same city since they moved from their hometown, others had moved between several cities. The group is not homogenous when it comes to their moving history, the reason why they moved, or the living conditions in the city. Five participants were under 18 years old when they moved, and two had been living in the city for 5 and 9 years. Three were over 20 years old when they moved, and they had lived in the city for 2-3 years at the time of the interview. None of them moved with their family but moved on their own and as a part of their independence from their nuclear families. Seven of the participants shared apartments with peers, relatives, girlfriends, or acquaintances. One had a one-room flat, and he had relatives in the city that he could visit. Just a few of them had children at the time of the interview, and none of them had the daily care of a child. 
Five of the participants moved because of education at university level, while three moved because of military service or job opportunity. In Norway, university education is free, and normally students are financing living expenses students with low-interest education loan. Attending university is common, despite the family's economy. It is not limited to highincome families or the cultural elite. Furthermore, most children attend to community primary school, which give an academic background suited for Norwegian universities. It means that a relative high number of adolescents from both cultural minority and majority attend a university education.

\section{Results and analyzes}

\section{The importance of actors; moving from relatives to friends}

All the participants talked about important persons in their life. It came apparent that these important persons had change when they moved. The people they came in connection to on daily base were important. They stressed the important of actors; people with a certain status. The status was not elite- or class related, but status in form of a person they could do something with. In the hometown, the important actors were relatives and kin. In the city, the important actor was friends. We understood them as pointing towards the important of having a person beside them.

All the participants emphasize relatives as significant others. They spoke of parents, grandparents, uncles and aunts, and all kind of kin, as close persons that they value and who plays a distinctive role in their life. This is not relationships that only plays a sentimental or emotional role but have a practical influence on their life. They tell us how they use to interact 
with them on a day-to-day basis. As we understand the participants, they consider these practical dimensions of being with another person and having actors in their daily life as important. To be close is does not necessarily have an emotional meaning, it seems to have a more practical meaning. They want to have real person to be close to, a person they want to do activities together with them. To capture this practical dimension, we have chosen the concept actors. Actors means persons who do something, is are active and aiming for something.

To demonstrate the weight the young men put on the importance of actors, we start this presentation with a reflection from one of the participants. "I once said that Sámi children become more independent and cope better [than others] because they have a large community surrounding them; they have cousins, grandparents...". As we can see from this reflection, the relatives in the hometown give them a broad network that supports them. Many different people are giving them different kind of support, but he also has some critical reflections. The participant goes on in his comments by saying: "You never needed to get to know new people». He goes on: "It is not only that you have to meet new people, you have get used to that they have another culture as well'. They lack experience in the important task when moving according to this participant; you have to learn to know new people. This is a crucial competence when moving to an unfamiliar city. Another of the participant told us how his girlfriend made him aware of the benefit of small talk. He had never had to learn small talk because his network in his hometown was either relatives or kin. After learning it, he realized that it is a tool to get to know new people. 
The young Sámi men continued to regard relationship with someone as important after moving to the city, but in another form. Instead of closeness to relatives, they became close to friend as peers. Because closeness was to do something with another, they could reinvent how to be together in order to get new relationships in the city. The young men from the same village kept together and valued their fellowship. However, they also worked hard to make new friends.

There was two different kinds of actors after the moving process. First, relationships with the friends from the hometown whom they were able to relax with because they shared the Sámi culture and language and often were relatives. Second, acquaintance with someone from the city. The young men highlighted the importance of both kind of actors to enhance that the moving shall succeed regarding thriving and well-being.

\section{The importance of activities; changing of masculinity when moving from desirable duties to} leisure activities

The participants had a mutual attention to activities, both when they talked about experiences in their hometown and in the city. Everybody had been participating in practical duties and had pleasant memories from this. Some of them had affiliation to reindeer herding and had been largely involved in activities concerning this. Many did participate in duty activities like berry hunting, wood chopping, and snow clearing during childhood. Additionally, most of them were involved in sport activities, either organized or informal. Moving from the village to the city transformed their activities from desirable duties to leisure activities. By this transformation, also their masculinity transformed. In the rural village, participating in tradition activities defined manliness. In the city, however, participating in sport associated activities, gave access to the indigenous male community. 
Four came from reindeer herding families. They were involved in different types of practical work with the herding. The reindeers are moving from inland to coast between winter and summer. Hence, the reindeer herders are living a modern nomadic life, following the herd. We say modern, because it is a highly specialized and motorized moving process, affecting the entire family, but in a different way than it used to do. One of the participants described how he kept an open time schedule to make room for reindeer herding. "I don't normally join a weekend cottage trip but rather goes around about. I am at home, in the village, or join my grandfathers on the mountain trip. I am a lot at the rein camp [where the herd is at the time]". As we can see, he organized himself so that he could choose to "touch and go". In the hometown village, he kept an opening in the time schedule to the desirable duty task, but in the city the activities were more leisure oriented.

All the participants were engaged in practical task when they grew up. They described these tasks in positive wordings, and it came across as desirable activities. The relatives were often a part of the story; going to the mountain with grandparents or selling reindeer products to the tourist with their uncle. In the city, one of the participants told us that he had engaged in several new activities, as playing soccer and music. "And soccer; I use to play when I was younger, and when I moved to the city, I begun with soccer again".

After they moved to the city, activities were still important, but the kind of activities had changed. Practical tasks, as they had been involved with at home, were reduced to a minimum. The sports activity, however, had expanded. They replaced desirable duties with leisure activities. All of the participants were involved in sports activities. Even the ones that were not so athletic themselves had a role in sports related activities. 
All the young men talked about sports activities as fundamental for thriving and their wellbeing. It is not necessary the activity itself, the competition or the training, that is of importance. It is to belong to a community, which is of importance. The sport activities bring a togetherness that they value. "I was interested in establishing the club, and I went to the meeting because I wanted to get to know the people involved". When we follow their explanation of their interest in sports activities, we can see that the togetherness even had a deeper significance. It builds an arena for being Sámi in the city. Two citations can highlight this. 'When I was 16 years old, I wanted to be a sport athlete. The coach said nice things about me, and I got support from the club'. We ask the participant why he ended his contract with the club and became engage in establishing a new club. "It was to enhance the identity. When I trained in the first club, I had no feeling of identity, I felt nothing. It is not my club, you see. No belonging". Later he deepened his point by adding: "The new club is a better offer, frankly speaking, it is good...we try to promote the Saminess".

\section{The importance of birget as an aim; moving life-prospects from the familiar to the unfamiliar}

The new club the participants above refers to is of special interest for us. In one of the cities, several of the young Sámi men had established a new sport club. This club was not only about keeping up the active sports-life they knew from home. It was also to make an arena to live as Sámi. The sport club was engaging the athletes, but also those who preferred other roles, as economist, organizer and so on. The club acted as an arena to be together, to participate in a Sámi community. To enhance their situation after the moving process, the young men made a new arena for them self and the new actors with whom they interacted. They made themselves an area to move from doing desirable duties to leisure activities. The young Sámi men 
redefined and reinvented the activities in the context of the city and made room for being a young Sámi man in the city.

To establish a sports club as an arena to be Sámi in the new city, we analyze as a way to move the hometown activities into new contexts. Furthermore, we understand it as a way to make infrastructures for relationships with new kind of actors. In sum, we interpret it as an important part of taking control over the transition of relationships and activities. They use the arena they have created to master their situations. To birget, they would call this.

We asked them what they considered as masculinity. The participants understood almmáivuohta as something you do together and yet being independent. Almmáivuohta has to do with taking responsibility, they said. Almmáiduvvat were linked to physical and psychological challenges. They sum it up by connecting almmáivuohta, almmáiduvvat and birget. It is about coping, to cope together with others, showing respect to others and to manage life. Everybody said that to care for others was almmáivuohta, and all of them draw connection between almmáivuohta and well-being. None mentioned winning, being strong, or to be an individualist.

The participants describe how they by different means managed the transition from being part of a majority in a familiar village to be a minority in an unfamiliar city. Despite these eights men's personal success in this transition, they expressed it as challenging. One said: "I think it is hard for young Sámi..." and expressed sympathy for the ones that did not handle the moving process. Everybody knew someone that did not manage it. The participators 
mentioned lack of arena where they felt at home as one of the reasons. Another said that suchlike challenges were one of the main motivations for him to contribute to establish the sport club. He knew people that felt rejected and did not attend other clubs because they knew so few. The sport club is offering an arena to manage the identity challenge some are suffering from. It facilitates the move from the familiar to the unfamiliar by making an arena to be creative about how to be a young Sámi man in an unfamiliar context.

\section{Discussion}

The young men in this study have experienced a transition from rural to urban places and from majority to minority contexts while they do what all young people experience in their adolescent; a transition from adolescents to adult. As every teenage parent know, this transition is hard enough without any extra processes going on. However, as many indigenous parents know, indigenous youth often have to go through this period at the same time as some other challenging processes taking place. Most of them are doing well and manage these processes well. However, because of the extra burden the long-term effect of colonization and suppression causes on psychological health and well-being (King et al., 2009), some young indigenous men find the multiple transition process difficult. They would benefit from more and better support in this period.

Our questions for the discussion how the young men are managing and handling these transitions and what are their reflection about this. We are aiming to identify useful elements for social workers wanting to enhance young indigenous men's well-being in transition. The interviews reviled three main dimensions the young Sámi men activated to manage their 
transitions: actors, activities, and aims. These three dimensions facilitated the transition in different ways, enhancing different aspects of the moving process.

(Model 1: The three A's to enhance well-being for indigenous young men in transition here)

\section{Actors}

We can see a transition in the actors before and after the moving process. The young Sámi men do not interact with the same kind of people in the hometown as in the city. While they were close to relatives at home, they are leaning on friends and peers in the city. The consistent element is not the type of relationship; the stable elements are strong and predictable relationships.

In the rural village, these relatives are actors in the young Sámi men's life that came with "birth". The young men did not have to work to maintain the relationships with their relatives. In the city, however, they needed to learn how to establish new relationships and how to maintain those already made. Hence, some of the young men addressed the need to learn the skills for making new relationships, as small talk, getting to know new people, and to expand the personal network. In order to thrive in the new contexts in the city, these skills were necessary. For some, these relational technics were no easy tasks, and something most of them never had been reflection upon before they had to move. Because they had to change relationships from relative to friends and peers, they learned that to make friends was something they had to do, but not used to do. 
Social relations are one of the four dimensions that cause well-being according to the salutogenic model (Lindström \& Eriksson, 2005). To enhance the well-being for young men on the move, paying attention to the process of creating new relationships is important in order to support sense of coherence. The task is not complicated neither to learn nor to involve in an intervention. However, the young men might profit profoundly from it.

\section{Activities}

The establishing of a new sport club demonstrated several points of interest in order to debate experiences and reflections concerning moving. Even more, it demonstrated several issues regarding how to support young indigenous men on the move. Firstly, the young men established the sport club because they felt they needed somewhere to be Sámi. Secondly, they did it because they needed an arena to meet new people in familiar context. Thirdly, they did it because they needed an arena to transform their desirable duties into activities that fit the city context, but still were desirable.

As we can see, the sport club was not merely a place to do sport. To start up a sport club was to create a room to be in the city. To be a Sámi in the city, to be a young man in the city, and to be a friend. Additional it was a place to become using concept from Hall (1996): To become a Sámi in the city, instead of a Sámi in the hometown. To become a man in the city, instead of a man at home. Almmáiduvvat was not the same in the city as in the hometown. To establish the sport club was to create a room for almmáiduvvat. This is in line with Nystad (2003) when she explain almmáiduvvat as achieving power and mastering activities. 
The sport club was also a place to hold onto their relationships and to hold onto their ethnicity. Additional it was a place to expand relationships and reinterpret their way of being Sámi. Dankertsen (2014) has taught us about the grey zone between the Sámi and the Norwegian and the way it opens up intercultural rooms where the young Sámi can interpret ethnicity in new ways. The young men describe the sport club as being a place that helps them to create such intercultural rooms. The sport club is an infrastructure to create such intercultural rooms.

In the village, the young men spent time on desirable duties. Moving to the city, they transformed these desirable activities to leisure and sport activities. The sport club represented a place to do this. The sport club facilitated competence to adjust the regular, familiar activities at home into new competences. To transform desirable activities such as berry picking, hunting, reindeer herding, and wood chopping, into new activities, is necessary when a young man has to move to the city. These activities are just too rare in the city. Hence, the young men had to reinvent how to use his leisure time. When they established the sport club, they did not only establish a place to be active. They also established a place to support each other in the transformation from rural to urban life. In the sport club, with the diverse role to take, they made up a place to try new roles and play around with the familiar and the unfamiliar. Because it was a Sámi sport club, they had the infrastructure to continue to be in a majority situation. However, since it was a grey zone, as Dankertsen (2014) calls it, it became a place with crossroads of different identities. They can take on and mix multiple roles but do so in safe environment. This gives the young men the arena to take power over their situation when moving from a majority situation to a minority situation. They adjust to the city life with backing from a place where they are not always a minority. They practice tasks and skills necessary both as adult, man, and as citizens, by moving in and out of the familiar situations 
facilitated by the sport club. This enhance them to cope when different identities meet and collide.

In order to find elements for invention to enhance young indigenous men who experience problems when they have to move from the familiar majority base, the sport club might serve as an example. It is hard for young men to be thrown into a world where all their known identities become challenged and multiple new ones are presented. A crossroads of identities and conflicting categories give opportunities, but also some possible suppression. The way the sport club gave the young Sámi men room for moving from the familiar to the unfamiliar, to play with different roles, should be a foundation for an intervention that aim to enhance young indigenous men on the move.

\section{Aims}

Birget is the aim for the upbringing of a young Sámi man, according to the fathers (Boine 2007). To raise a Sámi boy is to aim for a young man that cope in life independent and cope together with people. From the interviewed with the Sámi men, we have seen how they have used the new sport club as an arena to manage the city life. They have birget by making an arena to be together, but also to learn to get new friends. They birget in familiar contexts and used it to birget in unfamiliar contexts. For a Sámi father that must be as feeling he succeeded in his upbringing. Addition, the sport activities gave new arenas to display indigenous masculinity (K. Anderson \& Innes, 2015). The sport club was not merely a sport club; it was a Sámi sport club. Furthermore, the Sámi sport club gave direction for the young men for their cultural identity. In order to create a place for them to be Sámi in the city, they used the sport 
club as a place to be Sámi. This is in line with how Stuart Hall (1996) describe identity as something in continuous creation.

The young Sámi men demonstrate how they manage to cope in new contexts, and this being the main reason why their experience their transition from the hometown to the city as successful. Even though they did not experience it as easy, they used their strength to master the situation, that being the ambition to birget as almmáivuohta in new contexts together, yet independent.

For a person it is important that the activity is social valuable and meaningful. The young Sámi men have used their coping abilities - their birget - to make sports activities their infrastructure to transfer the city life without losing themselves. The term "losing themselves", we understood as losing their saminess, their sense of belonging, or their lifeprospects. We interpret this as being experiences of powerlessness as demonstrated in the theory of intersectionality (Olsen, 2018). When their reflected upon the one that did not succeed in the transition, we understand it as being men that were about to lose themselves.

To move between different cultural contexts, as the young men we have interviewed manage, is a competence that provide recourses in transition processes. Social workers that aim to enhance young men on the move, have to support them to adapt to new contexts. At the same time, they have to enhance the young Sámi men in the process of having strategies to handle multiple- and colliding identities. This to avoid being vulnerable for power and structural forces in the societies affecting them negative. 


\section{Conclusion}

This study identifies three important dimension that are in transition when indigenous men are on the move from rural villages to urban cities and from being a part of a majority to be a part of a minority; actors, activities, and aims for the future. The three A's model captures these dimensions and is a potential tool for social worker to enhance well-being for young men on the move. The social workers need to address all of these three dimensions. If a social worker got the idea to support young men to establish a sport club to assist a transition process, and he went on stressing the winner-looser culture, he would fail if he meets the young Sámi men we have been interviewing. Their frame of references was not a winner culture or individual success; rather it was to be together, yet independent.

The young Sámi men we have been interviewing experienced a transition from relatives to friends and peers, from desirable duties to leisure activities, and used their skills to birget as a tool to manage the challenges in the moving process. Young men from other indigenous people might experience other variation in transition in regard to relationships, activities, and aims. However, we expect them to experience that the moving process would address these three dimensions. It is because the long-term effect of the harsh colonization politic towards indigenous people are similar. Furthermore, we expect them to recognize them as important parts of the transition. It is because we believe that young indigenous men are under similar stress around the world. 
For social workers that aim to enhance young indigenous men on the move, we have been discussing three suggestions. First, we gave the social workers the advice to pay attention to the new actors the young Sámi men can relate to. Second, we said that the foundation of an intervention should be to make room for the young men to play with different roles and different identities. Thirdly, we argued that the references for the intervention have to be the frame of references in the young men's culture. We believe that the three A's to enhance transition for young men on the move is a model social that workers can use as a framework. The model has the potential to be the structure for intervention to seek to enhance the wellbeing for indigenous young men on the move. The model directs the social workers attention to the core changing dimensions in the transition. The model can guide the social workers to ask: How is this a moving process regarding relations? How is this a moving process regarding activities? How does this moving process affect the aims for the future for this person?

In the future, we propose to use the model in strategic intervention and to evaluate the outcome. It is essential to find interventions that support the young indigenous men, enduring the long-term effect of the suppression and colonization of indigenous people.

\section{Glossary}

almmáiduvvat: to become a man

almmáivuohta: manliness or masculinity

birget: to handle or manage (together with) 


\section{References}

Anderson, I., Crengle, S., Leialoha Kamaka, M., Chen, T.-H., Palafox, N., \& Jackson-Pulver, L. (2006). Indigenous health in Australia, New Zealand, and the Pacific. The lancet, 367(9524), 17751785. Retrieved from http://www.sciencedirect.com/science/article/pii/S0140673606687734. doi:https://doi.org/10.1016/S0140-6736(06)68773-4

Anderson, K., \& Innes, R. A. (2015). Indigenous men and masculinities : legacies, identities, regeneration.

Armenta, B. E., Whitbeck, L. B., Habecker, P. N., \& Lee, R. M. (2016). The Historical Loss Scale: Longitudinal Measurement Equivalence and Prospective Links to Anxiety Among North American Indigenous Adolescents. Cultural Diversity and Ethnic Minority Psychology, 22(1), 110. doi:10.1037/cdp0000049

Atkinson, J. (2002). Trauma trails, recreating song lines: The transgenerational effects of trauma in Indigenous Australia: Spinifex Press.

Bania, E. V. (2017). Educational Footprints and Psychosocial Factors in Multicultural Contexts in Arctic Norway. A Cohort and Registry Data Study among Sami and Non-Sami Students, 2003-2012. In: UiT The Arctic University of Norway.

Boine, E. M. (2007). Kultuvrralaš oaidnočuoggát ja dálkkodeapmi/ Kulturelle aspekter og behandling. Tidsskrift for psykisk helsearbeid, 4(1), 99-117. Retrieved from http://www.universitetsforlaget.no/?marketplaceld $=200$ \&languageld $=1 \&$ siteNodeld $=705300$

Boine, E. M., \& Saus, M. (2012). Saamelaisten isien kasvastusstregioita. Lauriala, A (Ed.) In Koulu ja pohjoisen pojat. Rovaniemi: Lapin yliopistokustannus. ISBN: 978-952-484-511-3.

Braun, V., \& Clarke, V. (2006). Using thematic analysis in psychology. Qualitative Research in Psychology, 3(2), 77-101. doi:10.1191/1478088706qp063oa

Broderstad, E. G., Brustad, M., Johansen, K., Severeide, P. I., \& Todal, J. (2015). Sámi logut muitalit 8 : čielggaduvvon sámi statistihkka 2015 (Vol. 1/2015). Guovdageaidnu: Sámi allaskuvla.

Dankertsen, A. (2014). Samisk artikulasjon : melankoli, tap og forsoning i en (nord)norsk hverdag. (nr. 16(2014)), Universitetet i Nordland, Fakultet for samfunnsvitenskap, Bod $\varnothing$.

Denzin, N., \& Lincoln, Y. (2006). The Sage handbook of qualitative research. Reference Reviews, 20(3), 25-26. doi:10.1108/09504120610655394

Eidheim, H. (1987). Aspects of the Lappish minority situation (Vol. 14). Oslo: Department of Social Anthropology, University of Oslo.

Gjerpe, K. K. (2013). "The best of both worlds" : conceptualising an urban Sámi identity. In T. Universitetet $\mathrm{i}$ (Ed.).

Granseth, T. (2015). Gjennomstrømming i videregående opplæring (E. G. Broderstad, M. Brustad, K. Johansen, P. I. Severeide, \& J. Todal Eds. 57 ed. Vol. 2015). Guovdageaidnu: Sámi allaskuvla.

Griffiths, K., Coleman, C., Lee, V., \& Madden, R. (2016). How colonisation determines social justice and Indigenous health-a review of the literature. Journal of Population Research, 33(1), 930. Retrieved from https://doi.org/10.1007/s12546-016-9164-1. doi:10.1007/s12546-0169164-1

Hall, S. (1996). Questions of cultural identity. London: Sage.

Johansen, Y., Kvernmo, S. E., Spein, A. R., \& Silviken, A. C. (2003). Nuorra Sámis (Vol. nr 1). Kárášjohka: Sámi dearvvašvuodadutkanguovddáš.

Keskitalo, P., Määttä, K. \& Uusiautti, S. (2011) Towward the practical framework of Sámi education. British Journal of Education Reserch. 1(2), 84-106 DOlhttps://doi.org/10.9734/jesbs/2011/v1i1\%20\&\%20217685

King, M., Smith, A., \& Gracey, M. (2009). Indigenous health part 2: the underlying causes of the health gap. The lancet, 374(9683), 76-85. Retrieved from http://www.sciencedirect.com/science/article/pii/S0140673609608278. doi:https://doi.org/10.1016/S0140-6736(09)60827-8 
Kirmayer, L. J., Brass, G. M., \& Tait, C. L. (2000). The Mental Health of Aboriginal Peoples: Transformations of Identity and Community. In (Vol. 45, pp. 607-616). Los Angeles, CA. Kuokkanen, R. (2000). Towards an "Indigenous paradigm" from a Sami perspective. The Canadian Journal of Native Studies, 20(2), 411-436.

Koukkanen, R. (2009) Achievements of Indigenous Self-Determination: The Case of Sami Parliaments in Finland and Norway, p. 97-114. In Indigenous Diplomacies (Beier, J.M. Ed.). Palgrave Macmillian, New York https://doi.org/10.1057/9780230102279

Lindström, B., \& Eriksson, M. (2005). REVIEW: Antonovsky's sense of coherence scale and its relation with quality of life: a systematic review. Journal of Epidemiology and Community Health, 59(6), 440. doi:10.1136/jech.2005.034777

Minde, H. (2016). Assimilation of the Sami : implementation and consequences (3rd ed. ed. Vol. 3/2016). Kautokeino: Gáldu - Resource Centre for the Rights of Indigenous Peoples.

Nyseth, T., \& Pedersen, P. (2014). Urban Sámi Identities in Scandinavia: Hybridities, Ambivalences and Cultural Innovation. Acta Borealia, 31(2), 1-21. doi:10.1080/08003831.2014.967976

Nystad, K. (2003). Mannen mellom myte og modernitet. Nesbru: Vett \& viten.

Olsen, T. A. (2017). Privilege, Decentring and the Challenge of Being (Non-) Indigenous in the Study of Indigenous Issues. The Australian Journal of Indigenous Education, 1-10. doi:10.1017/jie.2017.16

Olsen, T. A. (2018). This Word is (Not?) Very Exciting: Considering Intersectionality in Indigenous Studies. NORA - Nordic Journal of Feminist and Gender Research, 1-15. Retrieved from https://doi.org/10.1080/08038740.2018.1493534. doi:10.1080/08038740.2018.1493534

Olsson, S.E. \& Lewis, D. (2002). Welfare rules and indigenous rights: the Sami people and the Nordic welfare states. In Social Welfare with Indigenous Peoples. Dixon, J. \& Scheurell, R.P. (Ed.) Routledge, London. DOI https://doi.org/10.4324/9780203224106.

Paine, Robert. The White Arctic: Anthropological Essays on Tutelage and Ethnicity. St. John's: Institute of Social and Economic Research, Memorial University of Newfoundland, 1977.

Peters, E., \& Andersen, C. (2013). Indigenous in the city : contemporary identities and cultural innovation. Vancouver: UBC Press.

Porsanger, J. (2004). An essay about indigenous methodology. Nordlit, 8(1), 105-120.

Silviken, A. (2009). Prevalence of suicidal behaviour among indigenous Sami in northern Norway. International Journal of Circumpolar Health, 68(3), 204-211. doi:10.3402/ijch.v68i3.18336

Smith, L. T. (1999). Decolonizing methodologies: Research and indigenous peoples: Zed books.

Sørlie, K., \& Broderstad, A. R. (2011). Flytting fra byer fra distriktsområder med samisk bosetting (NIBR Ed.). Oslo NIBR/Uit Senter for samisk helseforskning.

Thagaard, T. (2009). Systematikk og innlevelse : en innføring i kvalitativ metode (3. utg. ed.). Bergen: Fagbokforl.

Wolfe, P. (2013). The Settler Complex: An Introduction. American Indian Culture and Research Journal: 2013, Vol. 37, No. 2, pp. 1-22.

Zhao, Y., You, J., Guthridge, S. L., \& Lee, A. H. (2011). A multilevel analysis on the relationship between neighbourhood poverty and public hospital utilization: is the high Indigenous morbidity avoidable? BMC Public Health, 11(1), 737. Retrieved from https://doi.org/10.1186/1471-2458-11-737. doi:10.1186/1471-2458-11-737 